\title{
Microsurgical Extrahepatic Cholestasis in the Rat: A Histopathological Liver Study
}

\author{
María-Angeles Aller ${ }^{*}$, Luis Ortega $^{2}$, Fernando Sánchez-Patán ${ }^{1}$, Raquel Anchuelo ${ }^{1}$, Arturo Cruz ${ }^{3}$, \\ Manuel Losada ${ }^{3}$ and Jaime Arias ${ }^{1}$ \\ ${ }^{1}$ Surgery I Department, School of Medicine, Complutense University of Madrid, Spain \\ ${ }^{2}$ Pathology Department, Hospital Clinico San Carlos, Madrid, Spain \\ ${ }^{3}$ General Surgery Unit, Hospital Virgen de la Luz, Cuenca, Spain
}

\begin{abstract}
Fibrosis, bile duct proliferation and mast cell hyperplasia characterize extrahepatic cholestasis. We studied these liver alterations in a new microsurgical model of extrahepatic cholestasis in the rat. Male Wistar rats: Sham-operated $(n=9)$ and Microsurgical Cholestasis $(n=10)$. After 4 weeks, a liver morphometric study was carried out using an image analysis system to assess bile proliferation and the fibrosis. The liver expression of alpha-smooth muscle actin was assayed by an immunohistochemical technique and mast cells were also counted. Cholestatic-rats presented portal hypertension, portosystemic circulation, and increased $(\mathrm{p}=0.0001)$ plasma bilirubin, alkaline phosphatase, Aspartateaminotransferase, Alanine-aminotransferase, and Lactate-dehydrogenase. Plasma levels of Albumin decreased $(p=0.001)$. Cholestatic-rats showed intense biliary duct proliferation $(p=0.0001)$ and fibrosis $(p=0.0001)$. Mast cells accumulate $(\mathrm{p}=0.0001)$ around proliferating bile ducts and fibrous septa. The microsurgical cholestasis in the rat induces fibrosis and hyperplasia of bile ducts and mast cells. Mast cell liver infiltration could be an etiopathogenic remodeling factor in experimental cholestasis.
\end{abstract}

Keywords: Cholestasis, microsurgery, mast cell, fibrosis, rat.

\section{INTRODUCTION}

The experimental model most widely used to study the extrahepatic cholestasis is based on common bile duct ligation (BDL). In essence, the bile duct is isolated, doubly ligated and resected between the two ligatures [1-7].

However, this technique can evolve bile recanalization as well as a bile pseudocyst, derived from the proximal bileduct. This bile cyst can therefore produce hepatopulmonary abscesses and sepsis $[8,9]$. We have proposed a microsurgical technique that consists in resectioning the extrahepatic bile via in order to avoid these severe and frequent complications [10].

The extrahepatic cholestasis models in the rat are very useful to study antifibrogenic therapies [11-13] and that is why we measure the fibrosis degree related to microsurgical extrahepatic in this study in order to assay future alternative therapeutics for biliary fibrosis.

The models of extrahepatic cholestasis in the rat are not only useful for evaluation of drugs and their effects on the secondary biliary fibrosis, but also to characterize this pathology [1]. Since mast cells are reported to participate in the development of liver fibrosis induced by bile duct resection [1], we have studied the existence of a relationship between the liver fibrosis grade and the mast cell number infiltrating

*Address correspondence to this author at the Departamento de Cirugía I, Facultad de Medicina, Universidad Complutense, Pza. de Ramón y Cajal s.n., 28040 Madrid, Spain; Tel: +34 91394 1388; Fax: +34 91 3947115;

E-mail: maaller@med.ucm.es the liver parenchyma in this new experimental model of microsurgical extrahepatic cholestasis.

\section{MATERIAL AND METHODOLOGY}

Male Wistar rats, with weights ranging between $230 \mathrm{~g}$ and $270 \mathrm{~g}$ from the vivarium of the Complutense University of Madrid were used. The animals were fed a standard laboratory rodent diet (rat/mouse A04 maintenance diet, Panlab, Spain) and water ad libitum. They were housed in a light/dark-controlled room (light cycles: 7:30a.m. -7:30p.m.), with an average temperature $\left(22 \pm 2{ }^{\circ} \mathrm{C}\right)$ and humidity $(65-$ $70 \%$ ) in groups of three to four animals.

The experimental procedures employed in this study agree with the principles and practices of the 1986 European Guide for the Care and Use of Laboratory Animals in accordance with Ethical Guidelines from European Community Council Directive $(86 / 609 / E E C)$ and published in Spanish Royal Decree 1201/2005.

\section{EXPERIMENTAL DESIGN}

The animals were divided into two groups: Shamoperated (SO) (Group I: $n=9$ ), in which the common bile duct was dissected, and microsurgical cholestasis (MC) (Group II: $n=10$ ) in which the resection of the extrahepatic biliary tract was performed $[10,14]$

\section{SURGICAL PROCEDURES}

Rats were anesthetized with Ketamine hydrochloride $(100 \mathrm{mg} / \mathrm{kg})$ and Xylazine $(12 \mathrm{mg} / \mathrm{Kg})$ i.m. Surgery was performed under aseptic but not sterile conditions. An abdominal midline incision was made and the intestinal loops 
were covered with wet gauze and shifted toward the left side of the animal to expose the hilar structures.

In Group I (SO), the bile duct and its lobular branches were dissected. In Group II (MC), the extrahepatic bile tract was resected using a binocular operatory microscope (Zeiss, OPMI 1-FR). First, the common bile duct was ligated (silk $4 / 0$ ) and sectioned close to the beginning of its intrapancreatic portion. This maneuver, which produces dilation of the extrahepatic biliary tract, facilitates the posterior dissection of the bile duct and the biliary branches of the four hepatic lobes, which make up the liver of the rat. Once the bile duct is sectioned, it is shifted upwards. The dissection and section between ligatures of all the biliary branches that drain the hepatic lobes is possible by using a binocular operatory microscope (Zeiss, OPMI 1-FR). First, the biliary branch (sometimes there are two branches) of the caudate lobe and then the two biliary branches of the right lateral lobe are dissected, ligated and sectioned close to the hepatic parenchyma. The upward dissection of the extrahepatic biliary tract makes it possible to individualize, ligate and section the biliary branches draining the middle lobe and, finally, the same procedure is followed with the biliary branch of the left lateral lobe. The dissection and section of the bile ducts from the four liver lobes of the rat must be done without injuring either the portal and, most especially, the arterial vascularization of these lobes [10, 14]. The abdomen was closed in two layers by continuous running sutures with an absorbable suture (3/0 Polyglycolic acid) and silk (3/0).

\section{Portal Vein Pressure Measurement}

Splenic pulp pressure, an indirect measurement of portal pressure (PP) was measured by inserting a fluid-filled 20gauge needle into the splenic parenchyma [15]. The needle was joined to a PE-50 tube, then connected to a pressure recorder (PowerLab $200 \mathrm{ML}$ 201) and transducer (Sensonor $\mathrm{SN}-844$ ) with a Chart V 4.0 computer program (ADI Instruments) and finally was calibrated before each experiment. The pressure reading was considered satisfactory when a stable recording was produced and respiratory variations were observed. The external zero reference point was placed at the midpoint of the animal, $1 \mathrm{~cm}$ above the operating table.

\section{Portosystemic Collateral Circulation Method}

Portosystemic collateral circulation was studied as follows. First, a midline abdominal incision with a large bilateral subcostal extension was performed and then the areas in which the collateral venous circulation developed, i.e. the splenorenal, gastroesophageal, colorectal and hepatic hilum, were carefully studied for the presence of increased collateral veins [16].

\section{Gross Mesenteric Vein Study}

Three grades of mesenteric venous vasculopathy were considered: grade 0: normal aspect of the branches of the superior mesenteric vein; without dilation and tortuosity related to the superior mesenteric vein compression for $30 \mathrm{sg}$; grade I: dilation and tortuosity of these branches related to this maneuver and grade II; in which the dilation and tortuosity of the branches of the upper mesenteric vein were spontaneous.

\section{Histopathological Examinations}

The animals were sacrificed by exsanguination and representative samples of the right lateral and the middle hepatic lobes were collected and fixed in phosphate-buffered neutral formalin $(4 \%)$ and embedded in paraffin. $5 \mu$-thick sections were stained with Hematoxylin \& eosine (HE), Masson's trichromic and Giemsa dyes to specifically stain fibrosis and mast cells. Furthermore, an immunohistochemical technique to measure the expression of alpha-smooth muscle actin (SMA) with an automatic staining machine (Techmate, DakoCytomation) was used. A mouse monoclonal antibody anti-actin (ref. Number MS-1295-P1, Westinghouse, LabVision/Neomarker), which has reactivity for different animal species including the rat, was used at 1:100 dilution as pretreatment for antigenic exposure, in a pressure cooker with citrate buffer. The binding with the primary antibody was revealed with diaminobencidine and the samples were contrated with hematoxilin \& eosin [17].

The morphometric study was carried out using an image analysis semi-automatic system (Microimage, Olympus) to objectively assess bile proliferation and the fibrosis content of the hepatic parenchyma. The mast cells stained with Giemsa, per $\mathrm{mm}^{2}$ of portal space and/or fibrotic tracts, were identified by the presence of multiple intacytoplasmic granules [18]. A minimum area of hepatic tissue was digitalized to $15 \mathrm{~mm}^{2}$ through microscopic images with a $10 \mathrm{x}$ lens.

\section{Statistical Analysis}

Statistical analyses were performed using SPSS software (Statistical Package for the Social Sciences, versión 14.00). The results are expressed as the mean \pm the standard deviation. Student $t$ test for unpaired data were used for the statistical comparison of the variables between the two groups. The relationship between the number of mast cells, bile proliferation and actin expression were verified using the Spearman coefficient correlation. The results are considered significant if $\mathrm{p}<0.05$.

\section{RESULTS}

\section{Portal Hypertension Signs}

In rats with cholestasis, the existence of portal hypertension was confirmed by the increase in portal pressure $(15.72$ \pm 2.28 vs $7.84 \pm 1.92 \mathrm{mmHg} ; \mathrm{p}<0.001)$ and the development of mesenteric venous vasculopathy, whether of grade II $(70 \%)$ or grade I $(30 \%)$, as well as of portosystemic collateral circulation $(100 \%)$ through splenorenal, paraesophageal and hemorrhoidal vessels.

\section{Serum Hepatobiliary Injury Parameters}

The rats with micosurgical cholestasis showed a significant increase $(p=0.0001)$, in the serum levels of direct bilirubin, alkaline phosphatase (AP), aspartate-aminotransferase (AST), alanine-aminotransferase (ALT), AST/ALT ratio and lactate-dehydrogenase (LDH) compared to sham-operated animals. On the contrary, plasma albumin levels decreased $(p=0.001)$ in rats with cholestasis (Table $\mathbf{1})$.

\section{Histopathologic Examination}

The SO animals did not show any histopathological change. On the contrary, in the animal with cholestasis, the 
Table 1. Direct Bilirubin (DB), Alkaline Phosphatase (AP), Aspartate Aminotransferase (AST), Alanin Aminotransferase (ALT), AST/ALT Ratio, Lactate Dehydrogenase (LDH), and Albumin in ShamOperated (SO) Rats and in Rats with Microsurgical Cholestasis (MC) 4 Weeks After the Intervention

\begin{tabular}{|c|c|c|}
\hline Group & SO $(n=9)$ & MC $(n=10)$ \\
\hline DB $\left(\mathrm{mg} \cdot \mathrm{dl}^{-1}\right)$ & $0.21 \pm 0.26$ & $6.81 \pm 1.76^{* * *}$ \\
\hline $\mathbf{A P}\left(\mathbf{U} \cdot \mathbf{L}^{-1}\right)$ & $129.28 \pm 32.53$ & $298.37 \pm 78.27^{* * *}$ \\
\hline $\operatorname{AST}\left(\mathbf{U}^{-L^{-1}}\right)$ & $65.56 \pm 10.07$ & $388.65 \pm 73.67^{* * *}$ \\
\hline ALT (U.L $\left.{ }^{-1}\right)$ & $40.46 \pm 6.78$ & $89.87 \pm 20.12^{* * *}$ \\
\hline AST/ALT & $1.45 \pm 0.19$ & $4.78 \pm 1.34^{* * *}$ \\
\hline LDH (U.L $\left.{ }^{-1}\right)$ & $384.80 \pm 98.93$ & $689.99 \pm 76.23^{* * *}$ \\
\hline Albumin (g/dl) & $2.97 \pm 0.12$ & $2.73 \pm 0.14 \mathrm{~g} / \mathrm{dl}^{* * *}$ \\
\hline
\end{tabular}

Mean $\pm \mathrm{SD} ;{ }^{* * *} \mathrm{p}<0.001$ : statitically significant value in relation to SO-rats.

hepatic parenchyma showed intense biliary duct proliferation $(\mathrm{p}=0.0001)$ in relationship with SO-rats (Table 2, Fig. 1). Masson's staining and immunohistochemical expression of actin showed an intense fibrosis that was quantified by digital image analysis $(p=0.0001)$ (Table 2, Fig. 1). Results obtained from mast cell counting are presented in Table 2 . The statistical analyses of the number of mast cell showed that in cholestatic livers mast cell infiltration was significantly $(p=0.0001)$ higher than those in the SO samples. Besides, the number of mast cells was superior in the right lateral lobe in relation to the middle lobe (Fig. 2). In the liver of cholestatic rats there was an accumulation of mast cells, particularly in portal spaces and in the fibrous septa, close to both, bile proliferation and fibrosis (Fig. 3). However, the number of mast cells was not correlated with bile proliferation $(\mathrm{r}=$ $1.40 ; \mathrm{p}=0.56)$ neither actin $(\mathrm{r}=-0.07 ; \mathrm{p}=0.77)$ in microsugical cholestatic livers.

Table 2. Liver Bile Proliferation, $\alpha$-Smooth Muscle Actin (SMA) Positive Cells and Mast Cell Infiltration in Sham-Operated (SO) Rats and in Rats with Microsurgical Cholestasis (MC) 4 Weeks After the Intervention

\begin{tabular}{|l|c|c|c|}
\hline \multicolumn{1}{|c|}{ Group } & SO $(\mathbf{n}=\mathbf{9})$ & MC $(\mathbf{n}=\mathbf{1 0})$ & P \\
\hline \hline Bile proliferation $(\mathbf{\%})$ & $4.02 \pm 3.04$ & $29.14 \pm 13.12$ & $\mathrm{p}=0.0001$ \\
\hline$(\boldsymbol{\alpha}-\mathbf{S M A}) \mathbf{n} / \mathbf{m m}^{\mathbf{2}}$ & $320.35 \pm 97.88$ & $1261.44 \pm 202.42$ & $\mathrm{p}=0.0001$ \\
\hline Mast cell $\mathbf{n} / \mathbf{m m}^{\mathbf{2}}$ & $69.47 \pm 49.66$ & $293.58 \pm 145.33$ & $\mathrm{P}=0.0001$ \\
\hline
\end{tabular}

Mean \pm SD. (The value of each rat is the mean of the middle and the right lateral lobe).

\section{DISCUSSION}

The microsurgical extrahepatic cholestasis in the rat makes it possible to obtain a model of biliary fibrosis 4 weeks after the intervention. Moreover, the hepatic histomorphometric study shows the coexistence of bile duct proliferation and mast cell accumulation in this experimental model. Fibrosis together with bile duct proliferation and mast cell accumulation in the liver is a characteristic change in experimental cholestatic liver disease [19, 20].
The extensive positive areas of alpha-SMA in rat livers of microresected extrahepatic bile via are principally located in the portal tracts and they are associated with proliferating bile ducts (Fig. 1). It has been demonstrated that the level of liver fibrosis can correspond to alpha-SMA and that alphaSMA is in turn a marker of activated hepatic stellate cells (HSC), a cell that represents the pivot of the fibrotic process $[6,21,22]$. Therefore, the obtained results related to the extension of alpha-SMA marker in the liver of rats with microsurgical extrahepatic cholestasis support the use of this experimental model to study, both the pathophysiological mechanisms involved in the liver fibrosis development and new anti-fibrogenic therapies.

HSC undergo a transition into alpha-SMA, expressing myofibroblastic-like cells in response to extrahepatic cholestasis [22]. Furthermore HCS activation is associated with stellate cell proliferation, increased contractility and enhanced extracellular matrix production $[11,22,23]$. Therefore, HSCs play a crucial role in cellular and molecular events that lead to hepatic fibrosis $[6,22,23]$.

Mast cells are widely distributed through virtually all vascularized tissues where they normally reside in close proximity to blood vessels and nerves [24]. They are specially numerous in anatomical sites that are directly exposed to the environment, including the gastrointestinal tract, airways and skin $[24,25]$. It has been recognized that mast cells are present in normal and pathologic livers in both humans and rats [26, 27]. A number of studies have found that mast cells are involved in various liver diseases [26, 28-30], thus showing that they play a broader role than originally thought [31].

Mast cells are reported to participate in the development of liver fibrosis in rodent and human models [28, 32]. Experimental studies have shown that bile duct ligation in rat, a model of liver fibrosis [1], caused an increase in intrahepatic mast cells [19, 27]. However, it is not yet known how the mast cells participate in liver fibrosis. Although given that bile duct ligation in the rat causes liver inflammation [33] and many mast cell mediators are considered to be proinflammatory $[24,25]$, it could be supposed that mast cell activation will influence liver fibrosis within the context of a chronic inflammatory response. In this way, fibrosis associated to tissue remodeling, both mediated by mast cells, would be one of the major consequences of the chronic liver inflammation $[25,34]$. Thus, it has been suggested that liver fibrogenesis resembles a wound-healing process leading to scar formation $[33,35]$.

Interactions between mast cells and fibroblasts are paramount in the genesis of fibrosis [36, 37]. It has been demonstrated that mast cells can communicate with fibroblast in a manner that leads to fibroblast activation and subsequent modulation of some aspects of extracellular fibrosis [37, 38]. However, the results of a study using mast cell-deficient $\mathrm{Ws} / \mathrm{Ws}$ rats suggested that an increase of mast cells in the liver may be associated with fibrosis, but was not a cause of fibrosis [39]. Moreover, recently it has also been shown that mast cells might participate in fibrolysis by producing matrix metalloproteinases (MMP)-1 throughout the late stages of experimental fibrosis and cirrhosis [40]. Since improved therapies of liver cirrhosis must be based on the understand- 
(A)

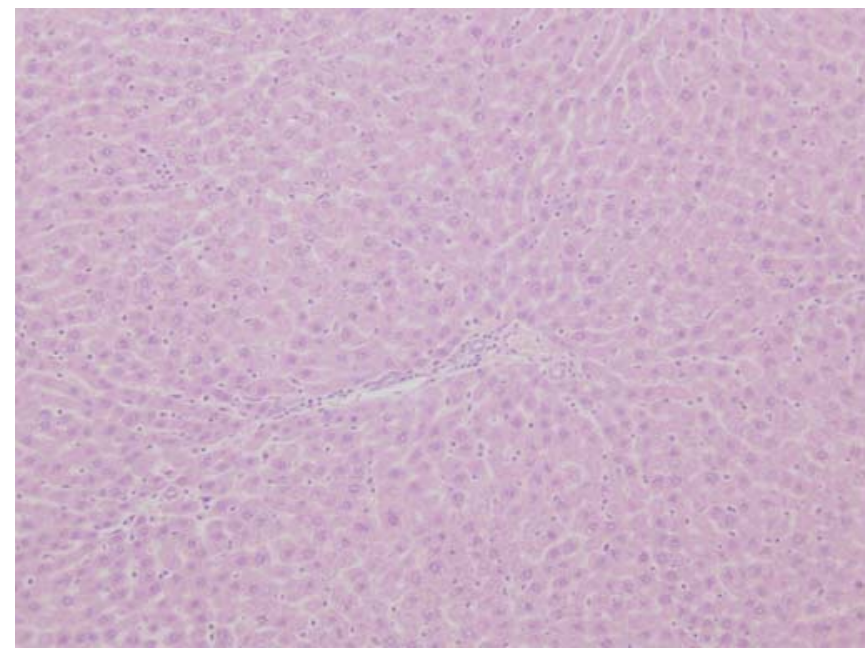

(B)

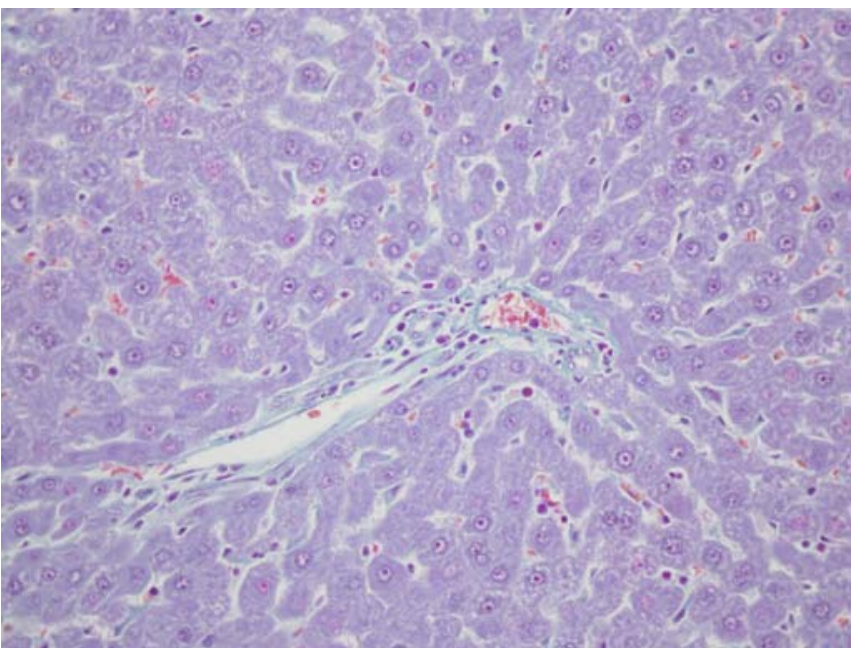

(C)

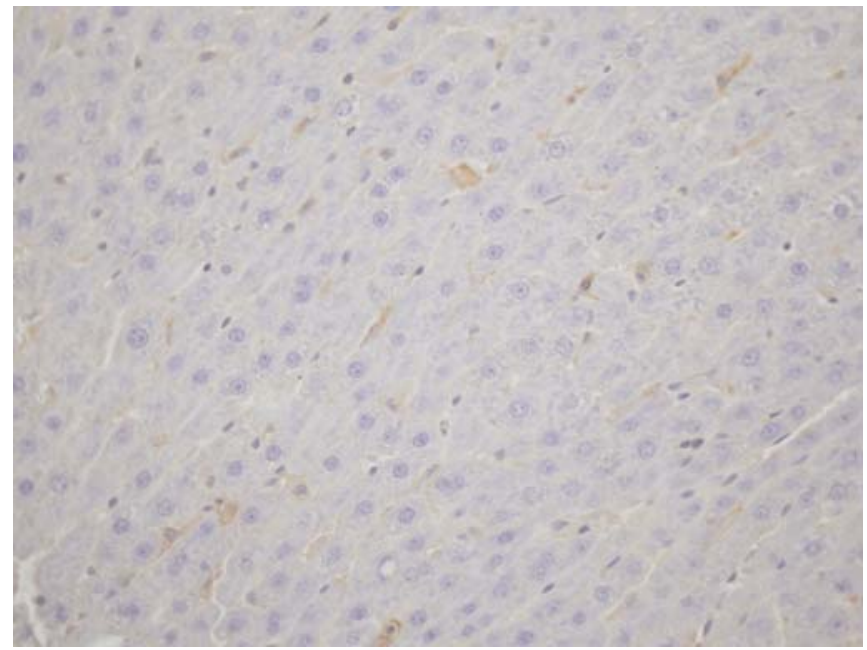

(D)

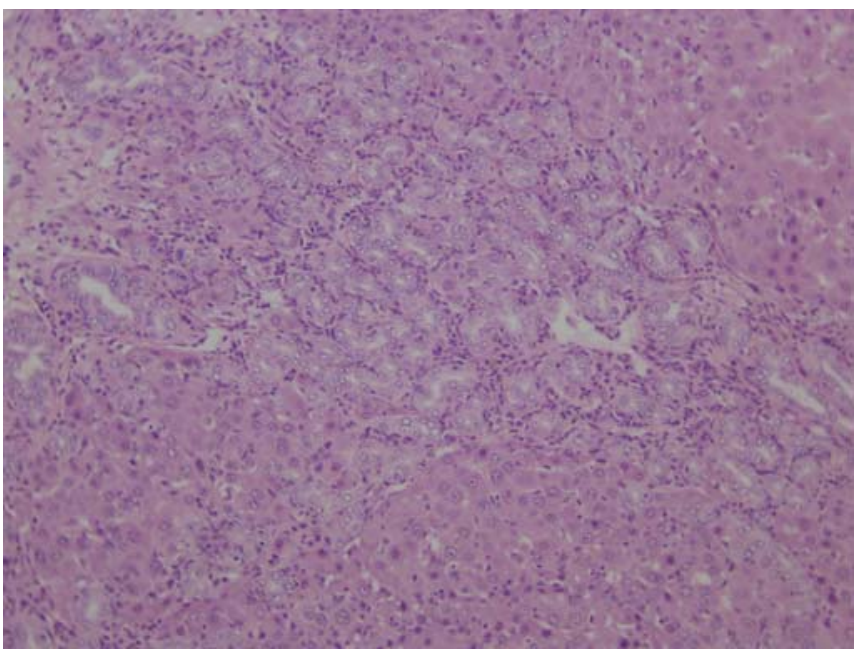

(E)

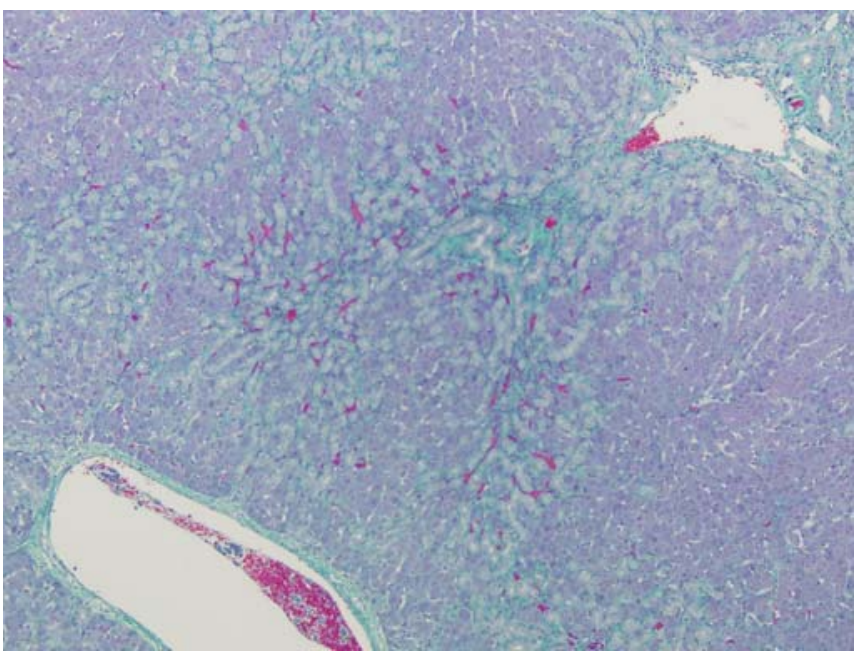

(F)

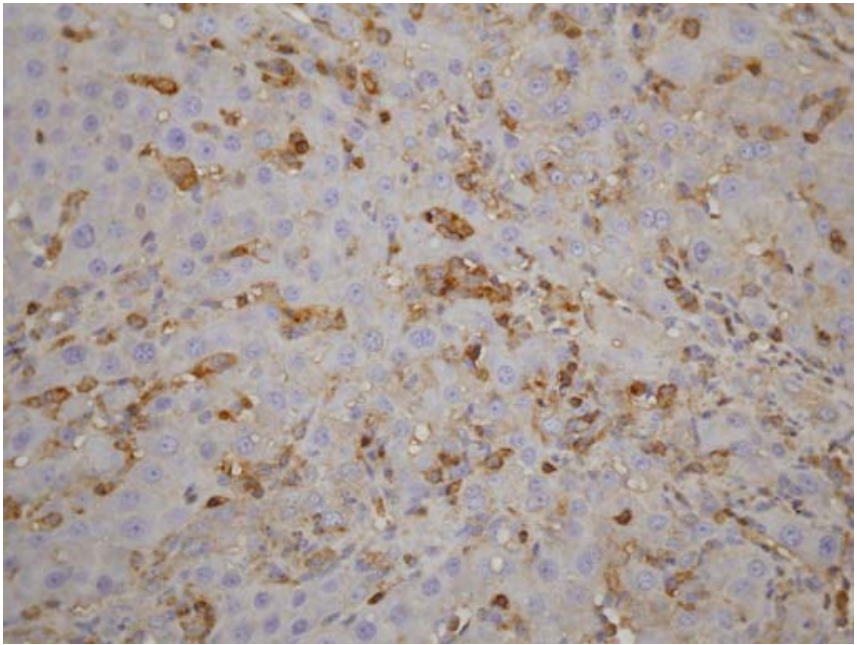

Fig. (1). Representative photomicrographs of liver from sham-operated (A, B and C) and microsurgical cholestatic-rats (D, E and F). Paraffin embedded sections were processed for H\&E (A and D); Masson trichromic (B and E) and immunohistochemical expression of alphasmooth muscle actin (SMA) (C and F). Extensive bile duct proliferation and peribiliary fibrosis (arrows) with bridging fibrosis was observed (original magnifications x 100, X 50 and x 200, respectively). 
(A)

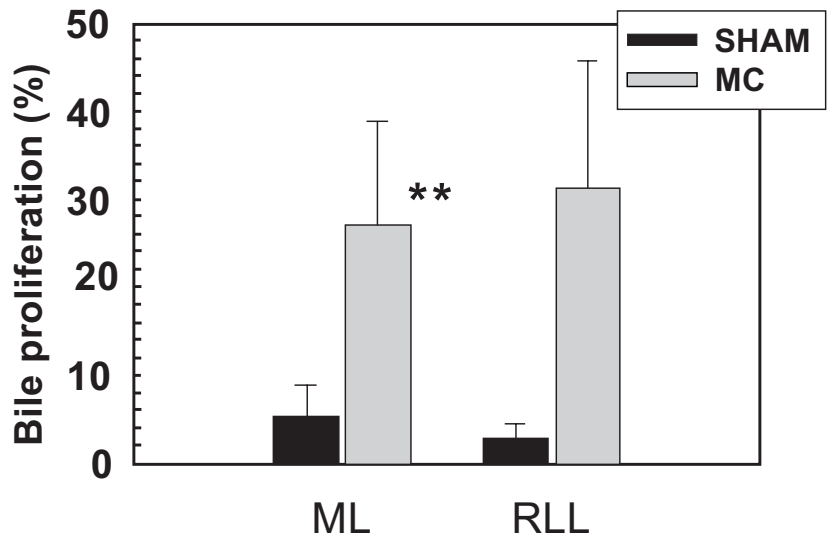

(B)

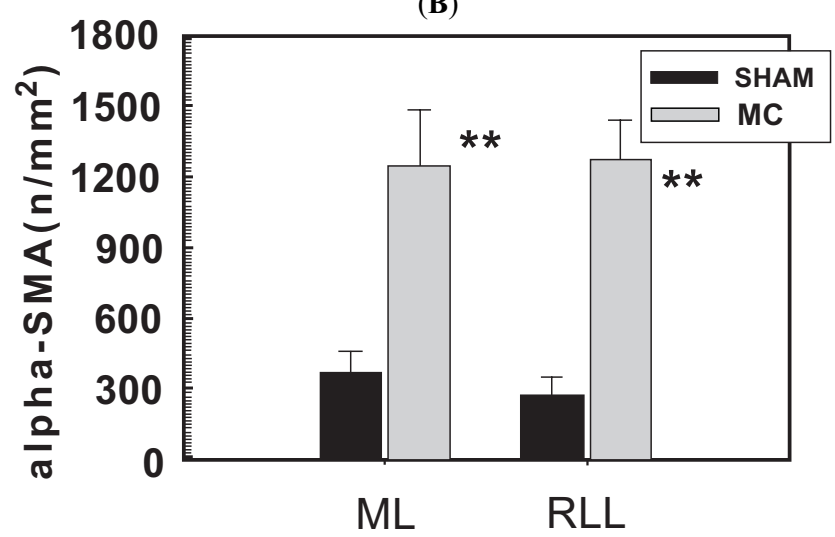

(C)

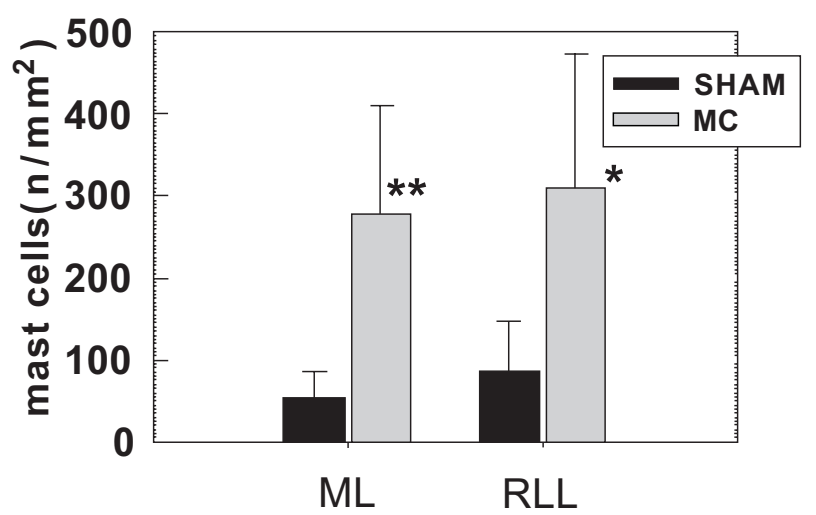

Fig. (2). Bile proliferation (A), alpha-smooth muscle actin (SMA) positive cells $(\mathbf{B})$ and mast cell infiltration $(\mathbf{C})$ in the liver of shamoperated rats (SO) and in microsurgical cholestatic rats (MC) 4 weeks after the intervention.

ing of its pathogenesis [41] a better understanding of this dual action, pro- and anti-fibrogenic of mast cells in the experimental related biliary fibrosis, would be of great interest $[42,43]$. In addition, chymase which is expressed by mast cells is also known to be an Angiotensin II-forming enzyme and Angiotensin II is a potent profibrogenic factor. Therefore, mast cells may contribute to liver fibrogenesis through chymase-dependent Angiotensin II formation [44].

Mast cell hyperplasia is associated with the proliferation of bile ductules during microsurgical extrahepatic cholestasis. These findings suggest that mast cells accumulating in the portal triads may be involved in bile duct proliferation.
However, the recanalization of the ligated common bile duct in the rat leads to an abrupt increase in liver mast cells and a rapid decrease in proliferated bile ductules [20]. That is why it has been suggested that the accumulation of mast cells during cholestasis resolution would be related to the induction of apoptosis of the biliary epithelial cells [20]. Apoptosis of the biliary epithelial cells may also be caused, among other factors, by hypoxia [45]. Thus, a pathological relationship between the bile pathway blood flow and its injury is established [46, 47].

(A)

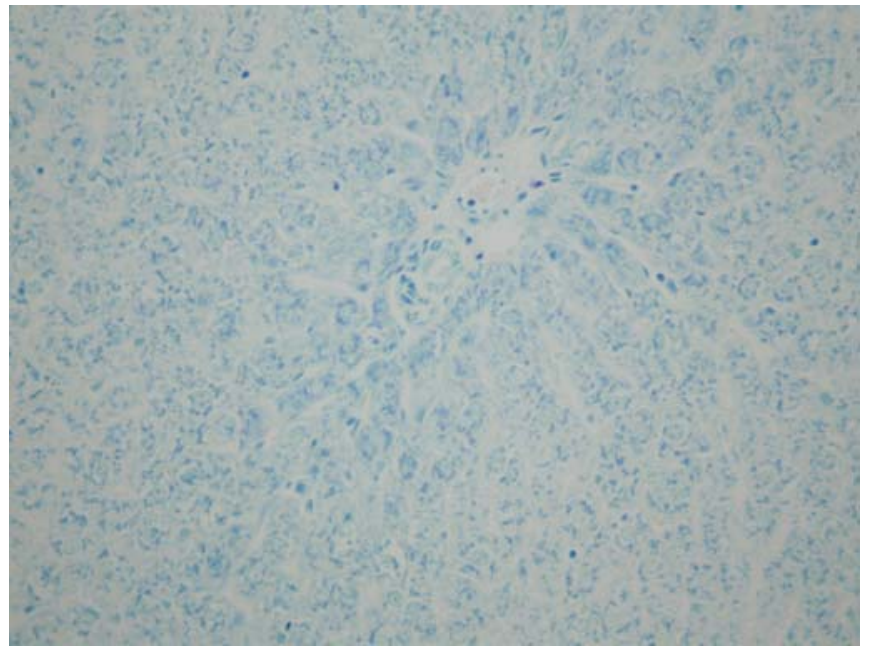

(B)

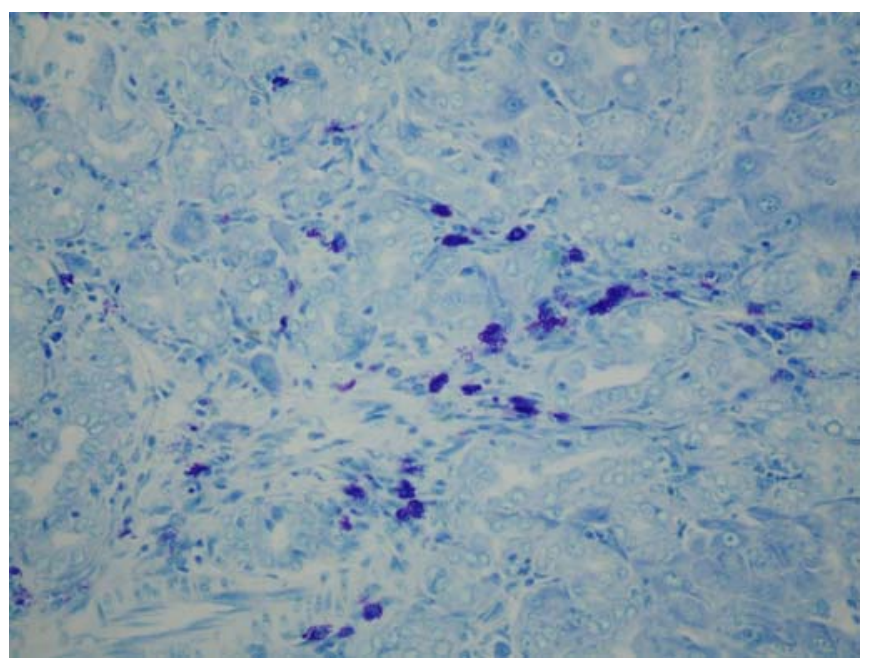

Fig. (3). Mast cells accumulate around proliferating bile ducts and fibrous septa in the liver of cholestatic-rats (B) compared with sham-operated animals (A) (Giemsa, X 200).

The intrahepatic and extrahepatic biliary tract is supplied and nourished by a network of fine vessels called the peribiliary vascular plexus derived from the hepatic arterial branches [47]. In extrahepatic cholestasis the injury to the peribiliary arterial plexus can result in ischemia and oxidative stress of the biliary tract $[9,48]$. After common bile duct ligation in the rat the enormous extension of the peribiliary vascular plexus suggests the important role of the arterial blood supply of the biliary tree in conditions of cholangiocyte proliferation, such as it occurs during chronic cholestasis [47]. Proliferation of the peribiliary arterial plexus by 
angiogenesis follows cholangiocyte proliferation. In both, the vascular endothelial growth factor (VEGF) plays a role $[47,49]$.

Mast cells in fibrotic livers can also be involved in hepatic arterialization. During the establishment of liver fibrosis the altered structure of the sinusoids resembles that of capillaries [50]. This change is known as "sinusoidal capillarization" and mast cells can be considered key elements in this process of transforming sinusoidal endothelial cells into capillary-type endothelial cells $[31,50]$. Capillarization hinders normal exchanges between plasma and hepatocytes and is the main cause of worsening liver function [50].

Therefore, it could be considered that the role developed by mast cells in the experimental extrahepatic cholestasis is dual, that is, it changes along the evolution of the cholestatic liver [42, 43]. If so, in early evolutive phases mast cells would participate in the pro-inflammatory process that induces biliary proliferation and fibrogenesis [27]. However, the prolonged cholestasis would favor the change of the mast cell environment and induce a switch in their phenotype, promoting fibrolysis by producing metalloproteinases and matrix degradation [40]. In this way, interferon-alpha and steroids may have antifibrogenic properties in limiting the actuation of stellate cells and by increasing the production of collagenase and metalloproteinase; steroids share similar antifibrogenic properties [51].

This supposed protective and antifibrotic role of mast cells in chronic cholestasis would explain the persistent increased number of mast cells in the development of both fibrosis and liver cirrhosis associated with the markedly decrease of myofibroblasts and macrophages in periportal regions [40]. Mast cells, owing to their periportal location, would induce bile epithelium apoptosis with attenuation of hepatocyte apoptosis and, therefore this may be another mechanism by which mast cells could promote an antifibrogenic activity as well as hepatocyte preservation $[52,53]$.

\section{CONCLUSION}

In summary, by correcting the epithelial imbalance produced by cholestasis between the two main types of hepatic epithelial cells, namely biliary (proliferation) and hepatocytic (with apoptosis), the mast cells would try to limit fibrosis characteristic of chronic liver inflammation. One protective role that in some circunstances mast cell assume to orchestrate inflammation [54].

\section{ABBREVIATIONS}

$\begin{array}{ll}\mathrm{ALT} & =\text { Alanine-aminotransferase } \\ \mathrm{AP} & =\text { Alkaline phosphatase } \\ \mathrm{AST} & =\text { Aspartate-aminotransferase } \\ \mathrm{BDL} & =\text { Bile duct ligation } \\ \mathrm{HSC} & =\text { Hepatic stellate cells } \\ \mathrm{LDH} & =\text { Lactate-dehydrogenase } \\ \mathrm{MMP} & =\text { Matrix metalloproteinases } \\ \mathrm{MC} & =\text { Microsurgical cholestasis } \\ \mathrm{PP} & =\text { Portal pressure } \\ \mathrm{SO} & =\text { Sham-operated }\end{array}$

SMA $=$ Smooth muscle actin

SPSS $=$ Statistical Package for the Social Sciences

VEGF $=$ Vascular endothelial growth factor

\section{ACKNOWLEDGEMENTS}

This study was supported, in part, by grants from the Department of Health. Castilla-La Mancha Regional Council (Refs. 04047-00 and PI-2007/64).

We are indebted to Maria Elena Vicente for her invaluable assistance in the preparation of the manuscript and Elizabeth Mascola for translating the manuscript into English.

\section{REFERENCES}

[1] Kounturas J, Billing BH, Scheuer PJ. Prolonged bile duct obstruction: a new experimental model for cirrhosis in the rat. Br J Exp Pathol 1984; 65: 305-11.

[2] Lee SS, Girod C, Braillon A, Hadengue A, Lebrec D. Hemodynamic characterization of chronic bile duct-ligated rats: Effect of pentobarbital sodium. Am J Physiol 1986; 251: 176-80.

[3] Chen YS, Ginés P, Yang J, et al. Increased vascular heme oxygenase-1 expression contributes to arterial vasodilation in experimental cirrhosis in rats. Hepatology 2004; 39: 1075-87.

[4] Bataller R, Gäbele E, Parsons CJ, et al. Systemic infusion of angiotensin II exacerbates liver fibrosis in bile duct-ligated rats. Hepatology 2005; 41: 1046-55.

[5] Minter RM, Fan MH, Sun J, et al. Altered Kupffer cell function in biliary obstruction. Surgery 2005; 138: 236-45.

[6] Zhang XL, Liu JM, Yang CC, et al. Dynamic expression of extracellular signal-regulated kinase in rat liver tissue during hepatic fibrogenesis. World J Gastroenterol 2006; 12: 6376-81.

[7] Abraldes JG, Pasarin M, Garcia-Pagan JC. Animal models of portal hypertension. World J Gastroenterol 2006; 12: 6577-84.

[8] Holmberg JT, Hederström E, Ihse I. A method to prevent recanalization of the transected bile duct in the rat. Scand J Gastroenterol 1985; 20: 428-32.

[9] Aller MA, Lorente L, Arias J. Hepatic artery ischaemia in rats with cholestasis. Different response of the lobes. J Hepatol 1991; 13: S87.

[10] Aller MA, Lorente L, Alonso MS, Arias J. A model of cholestasis in the rat using a microsurgical technique. Scand J Gastroenterol 1993; 28: 10-14.

[11] Siller-Lopez F, Sandoval A, Salgado S, et al. Treatment with human metalloproteinase- 8 gene delivery ameliorates experimental rat liver cirrhosis. Gastroenterology 2004; 126: 1122-33.

[12] Refik M, Comert B, Oncu K, et al. The effect of taurine treatment on oxidative stress in experimental liver fibrosis. Hepatol Res 2004; 28: 207-15.

[13] Imamura M, Ogawa T, Sasaguri Y, Chayama K, Ueno H. Supression of macrophage infiltration inhibits activation of hepatic stellate cells and liver fibrogenesis in rats. Gastroenterology 2005; 128 : 138-46.

[14] Aller MA, Duran M, Ortega L, et al. Comparative study of macroand microsurgical extrahepatic cholestasis in the rat. Microsurgery 2004; 24: 442-47.

[15] Dieguez B, Aller MA, Nava MP, et al. Chronic portal hypertension in the rat by triple-portal stenosing ligation. J Invest Surg 2002; 15: 329-36.

[16] Aller MA, Nava MP, Cuellar C, et al. Evolutive phases of experimental prehepatic portal hypertension. J Gastroenterol Hepatol 2007; 22: 1127-33.

[17] Pilmore HL, Yan Y, Eris JM, Hennessy A, Mc Caughan GW, Bishop GA. Time course of upregulation of fibrogenic growth factors and cellular infiltration in a rodent model of chronic renal allograft rejection. Transpl Immunol 2002; 10: 245-54.

[18] Hochegger K, Siebenhaar F, Vielhauer V, et al. Role of mast cells in experimental anti-glomerular basement membrane glomerulonephritis. Eur J Immunol 2005; 35: 3074-82.

[19] Mori V, Bartoloni F, Omer S. On the behaviour of mast cells in experimental cholostatic hepatopathy caused by ligation of the common bile duct. Arch De Vecchi Anat Patol 1966; 47: 1089-98. 
[20] Takeshita A, Shibayama Y. Role of mast cells in hepatic remodeling during cholestasis and its resolution: relevance to regulation of apoptosis. Exp Toxicol Pathol 2005; 56: 273-80.

[21] Friedman SL. Cytokines and fibrogenesis. Semin Liver Dis 1999; 19: 129-40.

[22] Issa R, Williams E, Trim N, et al. Apoptosis of hepatic stellate cells: involvement in resolution of biliary fibrosis and regulation by soluble growth factors. Gut 2001; 48: 548-57.

[23] Greupink R, Bakker HI, Bouma W, et al. The antiproliferative drug doxorubicin inhibits liver fibrosis in bile duct-ligated rats and can be selectively delivered to hepatic stellate cells in vivo. J Pharmacol Exp Therap 2006; 317: 514-21.

[24] Galli SJ, Kalesnikoff J, Grimbaldeston MA, Piliponsky AM, Williams CM, Tsai M. Mast cells as "tunable" effector and immunoregulatory cells: recent advances. Ann Rev Immunol 2005; 23: 749-86.

[25] Metz M, Grimbaldeston MA, Nakae S, Piliponsky AM, Tsai M, Galli SJ. Mast cells in the promotion and limitation of chronic inflammation. Immunol Rev 2007; 217: 304-28.

[26] Farrel DJ, Hines JE, Walls AF, Kelly PJ, Bennett MK, Burt AD. Intrahepatic mast cells in chronic liver diseases. Hepatology 1995; 22: $1175-81$.

[27] Rioux KP, Sharkey KA, Wallace JL, Swain MG. Hepatic mucosal mast cell hyperplasia in rats with secondary biliary cirrhosis. Hepatology $1996 ; 23: 888-95$.

[28] Armbrust T, Batusic D, Ringe B, Ramadori G. Mast cells distribution in human liver disease and experimental rat liver fibrosis. Indications for mast cell participation in development of liver fibrosis. J Hepatol 1997; 26: 1042-54.

[29] Yamashiro M, Kouda W, Kono N, Tsuneyama K, Matsui O, Nakanuma Y. Distribution of intrahepatic mast cells in various hepatobiliary disorders. An immunohistochemical study. Virchows Arch 1998; 433: 471-79.

[30] Matsunaga Y, Terada T. Mast cells subpopulations in chronic inflammatory hepatobiliary diseases. Liver 2000; 20: 152-56.

[31] Franceschini B, Ceva-Grimaldi G, Russo C, Dioguardi N, Grizzi F. The complex functions of mast cells in chronic human liver diseases. Dig Dis Sci 2006; 51: 2248-56.

[32] Matsunaga Y, Kawasaki H, Terada T. Stromal mast cells and nerve fibers in various chronic liver diseases: Relevance to hepatic fibrosis. Am J Gastroenterol 1999; 94: 1923-32.

[33] Ramadori G, Saile B. Inflammation, damage repair, immune cells, and liver fibrosis: Specific or nonspecific, this is the question. Gastroenterology 2004; 127: 997-1000.

[34] Bachelet I, Levi-Schaffer F, Mekori YA. Mast cells: Not only in allergy. Immunol Allergy Clin N Am 2006; 26: 407-25.

[35] Ramadori G, Saile B. Portal tract fibrogenesis in the liver. Lab Invest 2004; 84: 153-59.

[36] Gruber BL. Mast cells in the pathogenesis of fibrosis. Curr Rheumatol Rep 2003; 5: 147-53.
[37] Albrecht M, Frungieri MB, Kunz L, et al. Divergent effects of the major mast cell products histamine, tryptase and TNF-alpha on human fibroblast behaviour. Cell Mol Life Sci 2005; 62: 2867-76.

[38] Au SR, Au K, Saggers GC, Karne N, Ehrlich HP. Rat mast cells communicate with fibroblasts via gap junction intercellular communications. J Cell Biochem 2007; 100: 1170-77.

[39] Sugihara A, Tsujimura T, Fujita Y, Nakata Y, Terada N. Evaluation of role of mast cells in the development of liver fibrosis using mast cell-deficient rats and mice. J Hepatol 1999; 30: 859-67.

[40] Jeong WI, Lee CS, Park SJ, Chung JY, Jeong KS. Kinetics of macrophages, myofibroblasts and mast cells in carbon tetrachloride-induced rat liver cirrhosis. Anticancer Res 2002; 22: 869-78.

[41] Friedman SL. Reversibility of hepatic fibrosis and cirrhosis- is it all hype? Nat Clin Pract Gastroenterol Hepatol 2007; 4: 236-37.

[42] Aller MA, Arias JL, Arias J. The mast cell integrates the splanchnic and systemic inflammatory response in portal hypertension. J Transl Med 2007: 5: 44.

[43] Aller MA, Arias JL, Cruz A, Arias J. Inflammation: a way to understanding the evolution of portal hypertension. Theor Biol Med Model 2007; 4: 44.

[44] Komeda K, Jin D, Hayashi M, et al. Significance of chymasedependent angiotensisn II formation in the progression of human liver fibrosis. Hepatol Res 2008; 38: 501-10.

[45] Kerr JF. Shrinkage necrosis a distinct mode of cellular death. J Pathol 1971; 105: 13-20.

[46] Nakanuma Y, Hoso M, Sauzen T, Sasaki M. Microstructure and development of the normal and pathologic biliary tract in humans, including blood supply. Microscopy Res Tech 1997; 38: 552-70.

[47] Gaudio E, Franchitto A, Pannarale L, et al. Cholangiocytes and blood supply. World J Gastroenterol 2006; 12: 3546-52.

[48] Woolf GM, Vierling JM. Disappearing intrahepatic bile ducts: the syndromes and their mechanisms. Semin Liver Dis 1993; 13: 26175 .

[49] Gaudio E, Barbaro B, Alvaro D, et al. Vascular endothelial growth stimulates rat cholangiocyte proliferation via an autoctine mechanisms. Gastroenterology 2006; 130: 1270-82.

[50] Zimmermann A, Zhao D, Reichen J. Myofibroblasts in the cirrhotic rat liver reflect hepatic remodeling and correlate with fibrosis and sinusoidal capillarization. J Hepatol 1999; 30: 646-52

[51] Serpaggi J, Carnot F, Nalpas B, et al. Direct and indirect evidence for the reversibility of cirrhosis. Hum Pathol 2006; 37: 1519-26.

[52] Canbay A, Friedman S, Gores GJ. Apoptosis: the nexus of liver injury and fibrosis. Hepatology 2004; 39: 273-78.

[53] Ghavami S, Hashemi M, Kadkhoda K, Alavian SM, Bay GH, Los M. Apoptosis in liver diseases-detection and therapeutic applications. Med Sci Monit 2005; 11:337-345.

[54] Kinet JP. The essential role of mast cells in orchestrating inflammation. Immunol Rev 2007; 217: 5-7.

This is an open access article distributed under the terms of the Creative Commons Attribution License (http://creativecommons.org/licenses/by/2.5/), which permits unrestrictive use, distribution, and reproduction in any medium, provided the original work is properly cited. 